

\section{DISCLAIMER}

This report was prepared as an account of work sponsored by an agency of the United States Government. Neither the United States Government nor any agency Thereof, nor any of their employees, makes any warranty, express or implied, or assumes any legal liability or responsibility for the accuracy, completeness, or usefulness of any information, apparatus, product, or process disclosed, or represents that its use would not infringe privately owned rights. Reference herein to any specific commercial product, process, or service by trade name, trademark, manufacturer, or otherwise does not necessarily constitute or imply its endorsement, recommendation, or favoring by the United States Government or any agency thereof. The views and opinions of authors expressed herein do not necessarily state or reflect those of the United States Government or any agency thereof. 


\section{DISCLAIMER}

Portions of this document may be illegible in electronic image products. Images are produced from the best available original document. 


\title{
REDUCED GRAVITY BOILING AND CONDENSING EXPERIMENTS \\ SIMULATED WITH THE COBRA/TRAC COMPUTER CODE
}

\author{
Judith M. Cuta and William J. Krotiuk \\ Pacific Northwest Laboratory \\ Richland, Washington 99352
}

(509) $375-3673$

\begin{abstract}
$\underline{\text { ABSTRACT }}$
It is being recognized that there does not currently exist an adequate understanding of flow and heat transfer behavior in reduced- and zero-gravity. There is not a sufficient experimental fluid-thermal data base to develop design correlations for two-phase pressure losses, heat transfer coefficients, and critical heat flux limits in systems proposed for advanced power sources, propulsion, and other thermal management systems in space. Pacific Northwest Laboratory (PNL), is the lead laboratory for thermal hydraulics in the Department of Energy's Multimegawatt Space Power Program, and has the responsibility of developing microgravity thermal-hydraulic analysis capabilities for application to space nuclear power systems. In support of this program, PNL has performed a series of reduced-gravity two-phase flow experiments in the NASA KC-135 aircraft. The objective of the experiments was to supply basic thermal-hydraulic information that could be used in development of analytical design tools. (The tests were conducted in conjunction with Dr. Fred Best of


Texas A8M University, using an apparatus built at Texas A\&M for NASA-sponsored low-gravity condensing studies. PNL contributed a transparent quartz 8-mm ID boiler tube, with appropriate instrumentation, and provided trained personnel to operate the experiment on the $\mathrm{KC}-135$.

Several test points from the $\mathrm{KC}-135$ tests were selected for simulation with the COBRA/TRAC computer code. COBRA/TRAC is a two-fluid, three-field thermalhydraulic computer code designed for best-estimate analysis of transient multiphase flow in nuclear reactor primary coolant systems in normal gravity. The generality of its modeling approach and stability of its numerical scheme make it readily applicable to a wide variety of thermal-hydraulic systems and geometries. The only code modification made to run these simulations was the removal of the gravity terms from the phasic momentum equations.

The selected test points were chosen for a range on void fraction from very low $(\sim 25 \%)$ to very high $(\sim 90 \%)$. The COBRA/TRAC calculations showed reasonable agreement with the measured temperature data in the boiler. The calculated boiler pressure drop, however, was somewhat higher than the measured value for these tests, indicating that the normal gravity interfacial drag, and possibly the wall drag correlations in the code, are not accurate in a reduced gravity environment. The COBRA/TRAC calculations do not match the pressure and temperature measurements in the condenser at all well, indicating that the existing constitutive models in the code for condensation, wall heat transfer and possibly interfacial momentum exchange are not directly applicable to reduced gravity conditions. This paper explores various possible causes 
for the lack of agreement between the experiments and the simulation, with particular attention to the differences in the physical characteristics of two-phase flow in one $g$ and near zero $g$.

\section{INTRODUCTION}

Work on the U.S. Department of Energy (DOE) Multimegawatt (MMW) Space Nuclear Power Program performed by Pacific Northwest Laboratory, has demonstrated that an adequate understanding of low gravity flow and heat transfer behavior does not exist $[1,2]$. The existing reduced gravity experimental data base is insufficient to develop design correlations for two phase pressure drop, heat transfer coefficients, and critical heat flux limits. These correlations are needed for the design and development of advanced space based power, propulsion, and other thermal management systems.

To support efforts to develop analytical design tools for application to space based power systems, a series of reduced gravity two phase flow experiments were performed in the National Aeronautics and Space Administration (NASA) KC-135 aircraft. These tests were conducted in conjunction with Dr. F. Best of Texas A\&M University, using a test section built for NASA sponsored low gravity condensing studies [3]. PNL added a transparent boiler section with appropriate instrumentation to the test apparatus. The following sections discuss the experiment apparatus and results. Selected tests were simulated with the COBRA/TRAC computer code [4], and the results are compared to test 
data. These comparisons illustrate the capabilities and limitations of existing analytical methods for predicting low gravity fluid thermal behavior.

\section{KC-135 REDUCED GRAVITY EXPERIMENT DESCRIPTION}

Reduced gravity boiling and condensing experiments were flown on the NASA KC135 aircraft in November 1986 and April 1987. Dr. F. Best received support from NASA to study reduced gravity condensation of water under space station design conditions. To permit the study of low gravity boiling, PNL supplied an instrumented boiler consisting of an 8-mm ID quartz tube wrapped in a helix of nichrome wire. A schematic of the "once through" test assembly [5] is shown in Figure 1. Flow exiting the condenser was vented to the atmosphere outside the KC-135 aircraft. Pressure, temperature, heater power, flowrate, accelerometer and gamma densitometer measurements were recorded. Measuring station locations are shown on the loop diagram in Figure 2.

The experiment was modified before the April 1987 flight to accommodate increased flow rates and heat fluxes, and to improve instrumentation. Experiment conditions are shown in Table 1, with the changes between the two test flights indicated. Adiabatic nitrogen-water two phase flow visualization tests were also performed during the April 1987 flights. 


\section{KC-135 REDUCED GRAVITY EXPERIMENT OPERATION}

The test matrix for the April flights consisted of 15 boiling/condensing tests; 12 unique tests, plus 3 repeat tests, to be run on the first day of testing in the KC-135. Ten nitrogen/water adiabatic tests were run on the second day. The planned and actual conditions for these tests are listed in Tables 2 and 3 . The boiling/condensing test point flow rates would be expected to produce either stratified or slug stratified flow for a horizontal orientation in one g. The adiabatic tests were primarily at low flow rates, where the horizontal one $g$ flow regime would be slug, stratified slug, or bubbly flow.

The adiabatic tests were included in the full test matrix to obtain reliable two phase data at the lower flow rates. During the November 1986 tests, experience with the test section in boiling with very low flow rates had shown that the flow was very unstable, probably due to transition effects during a parabolic maneuver. The process of void formation in the boiler caused the flow to chug erratically, and even reverse direction periodically. This tended to obscure and overwhelm the hydrodynamic behavior of the two phase flow, making it difficult to interpret the significance of the data obtained at low flow rates.

In the KC-135, the test conditions were set up for a given test point in level flight, then data was taken during three successive zero g parabolas. This permitted three zero g periods of approximately 20 seconds for each test point, separated by a 1-minute-long period of acceleration at 1.7 to $1.9 \mathrm{~g}$ 's. The 
acceleration period ensured that the flow would be fully stratified before each transition to zero $\mathrm{g}$. For aimost every test point, the flow regime changed to annular flow immediately upon entering zero g. Data was taken continuously throughout the sequence of three parabolas for each test.

In addition to the instrument readings taken by the data acquisition system during the tests, recordings were made of the boiler and condenser flows using NASA high speed cameras and a Kodak high speed video imaging system. The NASA cameras operated at 2700 frames per second, and provided approximately 4 seconds of real time recording. The high speed video system was provided on a demonstration basis by Eastman Kodak's Spin Physics Division. It was operated at 1000 frames per second, and was capable of recording up to 30 seconds of real time.

\section{ACCEPTABILITY OF LOW GRAVITY AIRCRAFT TESTS}

For the two phase KC-135 tests to be acceptable, it must be ensured that the flow conditions reach a true steady state during the reduced gravity interval. Also, the acceleration in the reduced gravity interval must be low enough to represent zero gravity conditions. These conditions were met in the boiler; the data show unambiguously that the fluid in the boiler was at thermal equilibrium (constant heat transfer) throughout the reduced gravity interval, and the high speed video images indicate a stable flow regime. In the condenser, however, there was some evidence that full thermal equilibrium was not achieved at the lowest flow rates until late in the reduced gravity 
interval. This may have been due to sudden changes in the heat transfer rate at the transition to reduced gravity, since the temperatures were constant prior to entering the reduced gravity condition. The high speed films obtained in the condenser show that the flow field displayed no evolutionary changes, which indicates that momentum equilibrium was well established in the condenser in all tests. This is consistent with the observed behavior in adiabatic tests in drop towers and in the NASA Learjet [6].

The reduced vertical acceleration during the low gravity interval in the $\mathrm{KC}-135$ is higher than that obtained in space. The accelerations are typically about $0.02 \mathrm{~g}$ in the $\mathrm{KC}-135$, while in low earth orbit the acceleration of gravity is on the order of $10^{-4} \mathrm{~g}$. The parabolic trajectory of the $\mathrm{KC}-135$ results in the net vertical acceleration approximately following a parabolic curve. Figure 3 plots the analog signal from the vertical axis of the three-axis accelerometer in the $\mathrm{KC}-135$ for parabola 10 . It is typical of the parabolas flown on both days of testing.

The transitions into and out of reduced gravity take up about one third of the total interval, leaving approximately 15 seconds of each parabola with a relatively steady low gravity condition. Although conditions in the $\mathrm{KC}-135$ only approximate the gravitational environment of space, tests in drop towers and with small free-fall test sections have shown significant effects on fluid behavior in two phase flow in low gravity environments of only $0.16 \mathrm{~g}$ to $0.2 \mathrm{~g}$ and more limited experimental time durations. The $0.02 \mathrm{~g}$ acceleration in the 
KC-135, while not a perfect match to space conditions, is low enough to study low gravity fluid behavior.

\section{COBRA/TRAC COMPUTER CODE DESCRIPTION}

The COBRA/TRAC computer code was developed to predict the thermal hydraulic response of nuclear reactor primary coolant systems in severe accident conditions. The code provides a two-fluid, three-field representation of two phase flow, with a separate set of conservation equations for the continuous liquid, continuous vapor and entrained droplet field. The equations are solved using a semi-implicit finite difference technique on an Eulerian mesh. The code has extremely flexible noding capabilities for both the hydrodynamic field and the heat transfer solution.

Closure of the conservation equations is achieved by using constitutive relations to define interfacial mass transfer, interfacial drag, wall drag, wall and interfacial heat transfer, entrainment and deentrainment rates, and the thermodynamic properties of the fluid. COBRA/TRAC contains constitutive relations determined from physically based models of the relevant phenomena, but these are tailored to the conditions expected during postulated reactor transients. They are semi-empirical, in that they are verified with experimental data, and are applicable only over a limited range of conditions.

The constitutive relations in the code are verified for reactor operational and transient conditions (see Reference 5, Volume 4), but generality is not 
well established. However, the conservation equations solved by COBRA/TRAC are applicable to the flow field in the test section, and any solution difficulties can be attributed to the shortcomings of the constitutive relations when applied to reduced gravity conditions. The purpose of modeling the experiment with COBRA/TRAC is to evaluate the applicablity of the existing constitutive models to reduced gravity conditions, and determine the areas where improved low gravity constitutive models are needed.

\section{EXPERIMENT MODELING WITH COBRA/TRAC}

Results from parabolas 2, 9, and 10 were chosen as representative of the range of conditions encountered in the boiling and condensing tests. Parabola 2 is at high flow rate and intermediate power; parabola 9 is at high flow rate and high power; and parabola 10 is at low flow rate and low power. These parabolas were modeled with COBRA/TRAC, and the code predictions compared with the test data.

The COBRA/TRAC model of the test section is illustrated in Figure 4 . It consists of 31 fluid nodes, with 8 nodes in the boiler section, 8 nodes in the condenser, and 8 nodes in the condenser cooling jackets. Boundary conditions on the test section model were imposed by specifying the measured boiler inlet flow rate and the exit pressure at condenser measuring station C-P-10 (refer to Figure 2). (Post test analysis indicated that the pressure recorded at the condenser exit, C-P-11, was the stagnation pressure rather than the static pressure, so it was deemed an inappropriate boundary condition 
for the simulation.) The nodes modeling the condenser cooling jackets were given a constant inlet flow boundary condition of $1.14 \mathrm{~L} / \mathrm{min}$. The power input to the boiler was modeled with a heat flux boundary corresponding to test measurements of the power applied to the wires on the outer wall of the quartz tube.

Reduced gravity was simulated in the code by setting the gravity terms in the momentum equations to zero. No attempt was made to modify the value of $\mathrm{g}$ to follow the actual accelerometer readings for a given parabola. Constitutive relations that use the gravity acceleration constant, g, were not changed, nor was the existing vertical flow regime map. The COBRA/TRAC calculated results are compared to the time-dependent measured pressures and temperatures in the test section.

\section{Parabola 2 Comparisons}

Figure 5 shows the calculated temperatures in the boiler compared to the measured temperatures during the reduced gravity interval. The calculated liquid temperature is plotted, since it is believed that the measured temperature is from a fully wetted thermocouple. A plot of the calculated saturation temperature at the boiler exit is included for comparison. Both the measured and calculated temperatures increase with axial length but remain constant with time at a particular measurement point. The exit temperature predicted by COBRA/TRAC is slightly higher than the measured value, but the calculations are generally in good agreement with the measured data. 
Figure 6 shows the pressure drop across the boiler during the reduced gravity interval. The data shows variation with time, which is consistent with the flow pattern of intermittent surges of slugs of two phase fluid observed in the high speed video on similar test runs. These bubbly slugs appeared to bridge the boiler tube with a highly irregular and chaotic interface. The slugs were separated by intervals of relatively smooth thin film annular boiling flow. It is reasonable to assume that the pressure drop fluctuations correspond to the flow regime transitions associated with the formation and traverse of the boiler by the slugs. The large measured variations at the beginning and end of the reduced gravity interval are due to transitions into and out of the low gravity region.

The COBRA/TRAC calculation appears to be completely insensitive to these fluctuations in the flow field, since the drag relations in the code do not correlate this behavior. The code predicts a bubbly flow regime with a smooth unvarying pressure drop that is in general slightly larger that what was actually observed in the boiler.

The calculated temperatures and pressures in the condenser during parabola 2 are compared to the measured values in Figures 7 and 8 , respectively. These results indicate significant differences between normal gravity and reduced gravity conditions in the condensation process. Neither the temperature nor pressure predictions match the data well. 
The COBRA/TRAC calculations predict a gradual increase in liquid temperature with time. This could be due to predicting a higher condensation rate than actually occurred, or to a lower wall heat transfer rate. The former would cause the liquid temperature to increase due to the mass transport of condensed saturated vapor across the interface; the latter would result in increasing liquid temperature as insufficient heat was removed from the liquid through the condenser wall to the cooling jacket fluid. A combination of both factors could also produce this result.

The pressures predicted with COBRA/TRAC in the condenser are considerably lower than the corresponding measured values. These results indicate that the code does not predict a large enough pressure loss in the condenser. This is surprising, because the observed bubbly flow pattern in the condenser in reduced gravity has been predicted by COBRA/TRAC, and one would expect the drag forces to be similar.

Examining the measured pressure values in terms of pressure drop it can be seen that the pressure loss in the condenser is approximately $5.17\left(10^{3}\right) \mathrm{Pa}$ $(0.75 \mathrm{psi})$, while the code predicts a pressure drop of $0.345\left(10^{3}\right) \mathrm{Pa}(0.05 \mathrm{psi})$. The measured pressure drop seems unusually large for the flow conditions, since the equivalent single phase pressure drop in the condenser for this flow rate is only $0.069\left(10^{3}\right) \mathrm{Pa}(0.01 \mathrm{psi})$. This means that the two phase friction pressure drop multiplier must be on the order of 75 to produce the observed pressures in the condenser. (The equivalent multiplier based on the pressure drop calculated in COBRA/TRAC is approximately 5.) This does not 
seem reasonable, and there is no particular phenomenon unique to zero gravity conditions that would account for this extraordinarily high two-phase pressure drop.

It is in general bad form to castigate the data when one's favorite analytical tool fails to predict the measurements exactly. The results shown here seem to indicate an error in the data--ejther in the instrumentation or the raw data reduction algorithm--but it is also possible that there is some factor at work that has not been taken into account in the code calculation or the subsequent analysis. At this point one can only conclude that the repeatability of this phenomenon bears further careful study.

\section{Parabola 9 Comparisons}

Parabola 9 was at essentially the same flow rate as Parabola 2, but at higher power, and consequently had a higher void fraction. The measured data and the COBRA/TRAC simulations for this test are presented in Figures 9 through 12. The boiler temperatures calculated in COBRA/TRAC are compared to the measured values in Figure 9. The. code overpredicts the exit temperature but the calculations match the trend of the data.

The boiler pressure drop is plotted in Figure 10. The data show rapid fluctuations in the pressure. The COBRA/TRAC prediction shows less variability in the magnitude of the pressure drop. COBRA/TRAC predicts a bubbly flow regime in the boiler except at the boiler exit where annular flow is predicted. 
The high speed video from this test shows a stable annular film boiling pattern near the boiler exit. At the higher void fraction in Parabola 9, the constitutive relations for drag are predicting changes in the interfacial drag that are closer to the actual physical behavior observed. This implies that some work in flow regime mapping could greatly improve the capability for predicting pressure drop in two phase flow in reduced gravity near this range of flows and void fractions.

The condenser results are plotted in Figures 11 and 12. COBRA/TRAC predicts considerably higher temperatures in the condenser than the measured data. The calculated exit temperature provides evidence of a local flow reversal. The increasing ramp in data temperature at all three measuring stations indicates that flow in the condenser was not at thermal equilibrium in this test. The pressure data is essentially constant at each measuring station, indicating momentum equilibrium is well established (Figure 12).

COBRA/TRAC predicts annular flow at all condenser locations except channel 14 , and calculates large fluctuations in pressure in the condenser during the reduced gravity interval. These oscillations are probably due to inappropriate regime transitions being predicted, resulting in changes in predicted drag, based on the existing flow regime map in the code. The flow reversal at the condenser exit predicted by the code was not observed in the experiment, and probably accounts for most of the discrepancy between the measured and calculated results. 
Parabola 10 Comparisons

Parabola 10 was at low flow rate and low power. The temperatures measured in the boiler, which are shown in Figure 13, are clearly not of the liquid phase temperature. The calculated boiler exit temperature matches the data very closely. The behavior shown at the intermediate stations (B-T-9 and B-T-10) is obviously due to repeated partial dryout and rewetting of the thermocouple. Both the high speed video and the COBRA/TRAC prediction indicate a bubbly flow regime near the boiler exit.

At this low flow rate and void fraction, COBRA/TRAC predicts a steady pressure drop in the boiler, as shown in Figure 14. Following the same pattern as in the other tests, the measurements show rapid changes in the magnitude of the pressure drop. As with Parabola 2, the predicted pressure drop is generally higher than the measured values.

In the condenser, the data for this test shows thermal equilibrium had been attained in the reduced gravity interval (refer to Figure 15). The COBRA/TRAC predictions are slightly high at the condenser inlet. Since the calculated temperature was in better agreement with the measured value at the boiler exit, most of this difference is due to heat loss of $2^{\circ} \mathrm{C}$ to $3^{\circ} \mathrm{C}$ in the line connecting the boiler to the condenser, which was not modeled in the code. The calculated temperature matches the measured temperature at station C-T-9, indicating that the code has calculated approximately the correct heat removal from the coolant in the first section of the condenser. But the predicted 
temperature is high compared to measurements at the end of the second condenser section (C-T-10), indicating that not enough heat has been removed here. It is not clear whether this is due to actual change in the rate of heat removal from one section of the condenser to another, or to other effects.

Comparison of the calculated and measured pressures in the condenser, shown in Figure 16, again shows a very small pressure drop in the bubbly flow regime predicted by COBRA/TRAC, while significant pressure drop is shown by the data. The same comments noted in the discussion of Parabola 2 are relevant here. The cause of the large pressure drop in the condenser is not clear, and the phenomenon bears further investigation.

Flow Regime Mapping

The flow field was recorded on a Kodak high speed video motion-analyzer system and with NASA high speed cameras in 10 of the 24 parabolas. All eight test points are represented in the recorded parabolas. These points have been plotted in Figure 17 using the revised flow regime map developed by Dukler (see Reference 7) from reduced gravity data obtained in the NASA Learjet and in drop tower tests. When plotted with superficial gas velocity versus superficial liquid velocity, the KC-135 data fall very nicely within Dukler's regime transition boundaries. The one exception is a test that appears to consist of bubbly flow, when the flow regime map predicts annular flow. 
For very low gas velocity at both high and low liquid velocities, the flow regime was clearly a bubbly flow--small bubbles dispersed nearly uniformly in a liquid field. At higher gas velocities and somewhat lower liquid velocities, the flow consisted of well-defined slugs separated by regions of distinct annular flow. The slugs were in most cases very "frothy, containing many entrained bubbles, but the slugs contained enough liquid to clearly differentiate them from regions of annular flow with an exceptionally thick film, and very chaotic interfaces. At the highest gas velocities attained in these tests, the flow was indisputably annular, although on occasion interfacial waves were observed to momentarily bridge the tube entirely.

The single data point labeled as "bubbly" that appears in the annular flow regime may be a victim of hazy semantics and even hazier eyesight on the part of the experimenters. In some of these tests, the annular film appeared quite thick, and contained a significant number of small bubbles. On the "flat" video image, it was sometimes difficult to see the fluid interface clearly, particularly when the interface was distorted by waves traveling near the gas velocity. It is possible that this anomalous point was in annular flow, but with a thick bubbly film:

SUMMARY AND CONCLUSIONS

Table 4 summarizes the flow regime experimental observations and COBRA/TRAC predictions. The results of the simulations of this data with COBRA/TRAC show very clearly that the normal gravity constitutive models in these codes, 
particularly those for interfacial drag, are not general enough to be applied indiscriminately to reduced gravity two phase flow. It appears that the flow boiling process itself is not very much different, so that it is possible to correctly predict the heat transfer and local temperatures if appropriate reduced gravity flow regime maps are employed. However, the interfacial momentum exchange is not captured correctly, and new constitutive relations are needed for interfacial drag in addition to a corrected flow regime map. Differences are more clearly evident in condensing flow, as the data indicates that the actual pressure drop is much larger than those predicted with current constitutive relations. There is also some indication that condensation heat transfer rates might be substantially different in reduced gravity, as compared to one $g$.

It appears that the use of normal gravity relations, using corrected two phase reduced gravity flow regime maps, represents the best current design tool. This method, however, does not fully describe the flow and heat transfer behavior of two phase fluids in reduced gravity. These conclusions are based on a limited amount of data and therefore must be verified by future testing. More reduced gravity expérimental data is needed for two phase pressure drop, heat transfer, and mass transfer model development and verification. Critical heat flux data is especially needed since these relations are empirical, and no reduced gravity flow data or models are available.

Future tests should also address the limitations of the current experiment. For example, extensive normal gravity ground test comparisons and some "free 
float" experiments should be performed to verify the existing data and expand the data base. Ultimately ail data and models must be verified in long term low gravity experiments performed in space.

\section{Acknowledgments}

The experimental activities presented in this paper were supported by the U.S. Department of Energy and NASA Johnson Space Center. Additional funding was also obtained from Wright-Patterson Air Force Base. The computer analyses activities were supported by the U.S. Department of Energy and the Northwest College and University Association of Science.

The authors wish to acknowledge the efforts of Zenen I. Antoniak, James M. Bates, and Thomas E. Michener of PNL who helped to plan, construct, and operate the experimental apparatus. The help of Jeffery W. Samuels of Oregon State University in preparing the COBRA/TRAC models is also acknowledged. The cooperation of the Eastman Kodak Spin Physics Division is greatly appreciated. The use of their high speed video system greatly aided data interpretation.

\section{References}

1. Antoniak, Z. I. (1986) Two-Phase Alkali-Metal Experiments in Reduced Gravity, PNL-5905, Pacific Northwest Laboratory, Richland, Washington. 
2. Krotiuk, W. J., and J. M. Cuta (1987) "Low Gravity Fluid-Thermal Experiments," Presented at the Third Pathways to Space Experimental Workshop, Orlando, Florida, June 3, 1987.

3. Kachnik, L. J. (1987) "Design, Construction, and Testing of a Boiling and Convective Condensation Experiment for Use in a Microgravity Environment," Thesis submitted to the Graduate College of Texas A\&M University.

4. Thurgood, M. J. et al. (1983) COBRA/TRAC - A Thermal-Hydraulics Code for Transient Analysis of Nuclear Reactor Vessels and Primary Coolant Systems, Volumes 1-5, NUREG/CR-3046, PNL-4385, Pacific Northwest Laboratory, Richland, washington.

5. Best, F., and N. Faget (1986) Test Equipment Package for Microgravity TwoPhase Flow Project, NASA Johnson Space Center, Houston, Texas.

6. Dukler, A. E., J. A. Fabre et al. (1987) "Gas Liquid Flow at Microgravity Conditions: Flow Patterns and Their Transactions," Presented at the Symposium on Thermai Problems in Space Based Systems, ASME Annual Meeting, December, 1987. 
TABLE 1. Low Gravity Boiling/Condensing Experiment Description

Experiment Date

Operating Fluid

Experiment Type

Maximum Flowrate

Boiler Size

Boiler Active Length

Maximum Boiler Heating

Condenser Size

Condenser Active Length
$11 / 86$

Water

Open loop

$0.1 \mathrm{~L} / \mathrm{min}\left(33 \mathrm{~kg} / \mathrm{m}^{2}-\mathrm{s}\right)$

$8 \mathrm{~mm} \mathrm{ID}$

$0.86 \mathrm{~m}$

$3 \mathrm{~kW}$

$6 \mathrm{~mm} \mathrm{ID}$

$0.9 \mathrm{~m}$
$8 \mathrm{~mm}$ ID

$0.9 \mathrm{~m}$

$4 / 87$

Water

Open 1oop

$1 \mathrm{~L} / \min \left(330 \mathrm{~kg} / \mathrm{m}^{2}-\mathrm{s}\right)$

$8 \mathrm{~mm} \mathrm{ID}$

$0.86 \mathrm{~m}$

$5 \mathrm{~kW}$ 
TABLE 2. Test Matrix for Boiling/Condensing Flow in Reduced Gravity.

Average

Run Flow Rate Power Exit Void Parabola Flow Rate Power No. $(\mathrm{L} / \mathrm{min})\left(\mathrm{kg} / \mathrm{m}^{2}-\mathrm{s}\right)$ (W) quality fraction number $(\mathrm{L} / \mathrm{min})\left(\mathrm{kg} / \mathrm{m}^{2}-\mathrm{s}\right)$

\begin{tabular}{|c|c|c|c|c|c|c|c|c|c|c|}
\hline 1 & 0.91 & 307 & 3583 & 0.01 & 0.65 & $\begin{array}{l}1 \\
2\end{array}$ & 0.8 & & 270 & $31 \overline{60}$ \\
\hline 2 & 0.91 & 307 & 3934 & 0.02 & 0.75 & $\begin{array}{l}3 \\
4 \\
5 \\
6\end{array}$ & $\begin{array}{l}0.8 \\
0.7 \\
0.7 \\
0.6\end{array}$ & & $\begin{array}{l}270 \\
237 \\
237 \\
203\end{array}$ & $\begin{array}{c}3037 \\
3305 \\
3110 \\
-\end{array}$ \\
\hline 3 & 0.91 & 307 & 4987 & 0.05 & 0.83 & $\begin{array}{l}7 \\
8 \\
9\end{array}$ & $\begin{array}{l}0.8 \\
0.8 \\
0.8\end{array}$ & & $\begin{array}{l}270 \\
270 \\
270\end{array}$ & $\begin{array}{l}5163 \\
5160 \\
4671\end{array}$ \\
\hline 4 & 0.30 & 101 & 1194 & 0.01 & 0.65 & $\begin{array}{l}10 \\
11 \\
12\end{array}$ & $\begin{array}{l}0.4 \\
0.4 \\
0.3\end{array}$ & & $\begin{array}{l}135 \\
135 \\
101\end{array}$ & $\begin{array}{r}1049 \\
998 \\
1164\end{array}$ \\
\hline 5 & 0.30 & 101 & 2247 & 0.10 & 0.90 & $\begin{array}{l}13 \\
14 \\
15\end{array}$ & $\begin{array}{l}0.4 \\
0.4 \\
0.4\end{array}$ & & $\begin{array}{l}135 \\
135 \\
135\end{array}$ & $\begin{array}{l}2725 \\
2783 \\
3037\end{array}$ \\
\hline 6 & -0.45 & 152 & 3371 & 0.10 & 0.90 & $\begin{array}{l}16 \\
17 \\
18\end{array}$ & $\begin{array}{l}0.5 \\
0.5 \\
0.4\end{array}$ & & $\begin{array}{l}169 \\
169 \\
135\end{array}$ & $\begin{array}{l}3780 \\
3323 \\
3228\end{array}$ \\
\hline 7 & 0.45 & 152 & 2494 & 0.05 & 0.83 & $\begin{array}{l}19 \\
20 \\
21\end{array}$ & $\begin{array}{l}0.3 \\
0.5 \\
0.5\end{array}$ & & $\begin{array}{l}101 \\
169 \\
169\end{array}$ & $\begin{array}{l}2203 \\
2510 \\
2630\end{array}$ \\
\hline 8 & 0.45 & 152 & 1792 & 0.01 & 0.65 & $\begin{array}{l}21 \\
22 \\
23 \\
24\end{array}$ & $\begin{array}{l}0.5 \\
0.5 \\
0.4 \\
0.5\end{array}$ & & $\begin{array}{l}169 \\
169 \\
135 \\
169\end{array}$ & $\begin{array}{l}2030 \\
1902 \\
2064 \\
1919\end{array}$ \\
\hline $\begin{array}{r}9 \\
10 \\
11 \\
12 \\
13 \\
14 \\
15\end{array}$ & $\begin{array}{l}0.45 \\
1.20 \\
1.20 \\
1.20 \\
0.30 \\
0.45 \\
1.20\end{array}$ & $\begin{array}{l}152 \\
405 \\
405 \\
405 \\
101 \\
152 \\
405\end{array}$ & $\begin{array}{l}5127 \\
4544 \\
4778 \\
5246 \\
1194 \\
5127 \\
4544\end{array}$ & $\begin{array}{l}0.20 \\
0.005 \\
0.01 \\
0.02 \\
0.01 \\
0.20 \\
0.005\end{array}$ & $\begin{array}{l}0.92 \\
0.10 \\
0.65 \\
0.75 \\
0.65 \\
0.92 \\
0.10\end{array}$ & & & $\begin{array}{l}a \\
a \\
a \\
a \\
a \\
a \\
a\end{array}$ & & \\
\hline
\end{tabular}

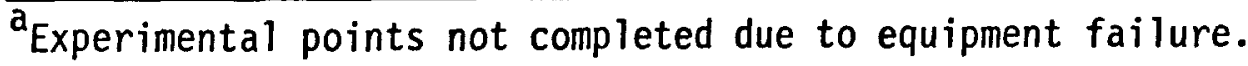


TABLE 3. Test Matrix for Adiabatic Two-Phase Flow in Reduced Gravity.

Planned Flow Rates

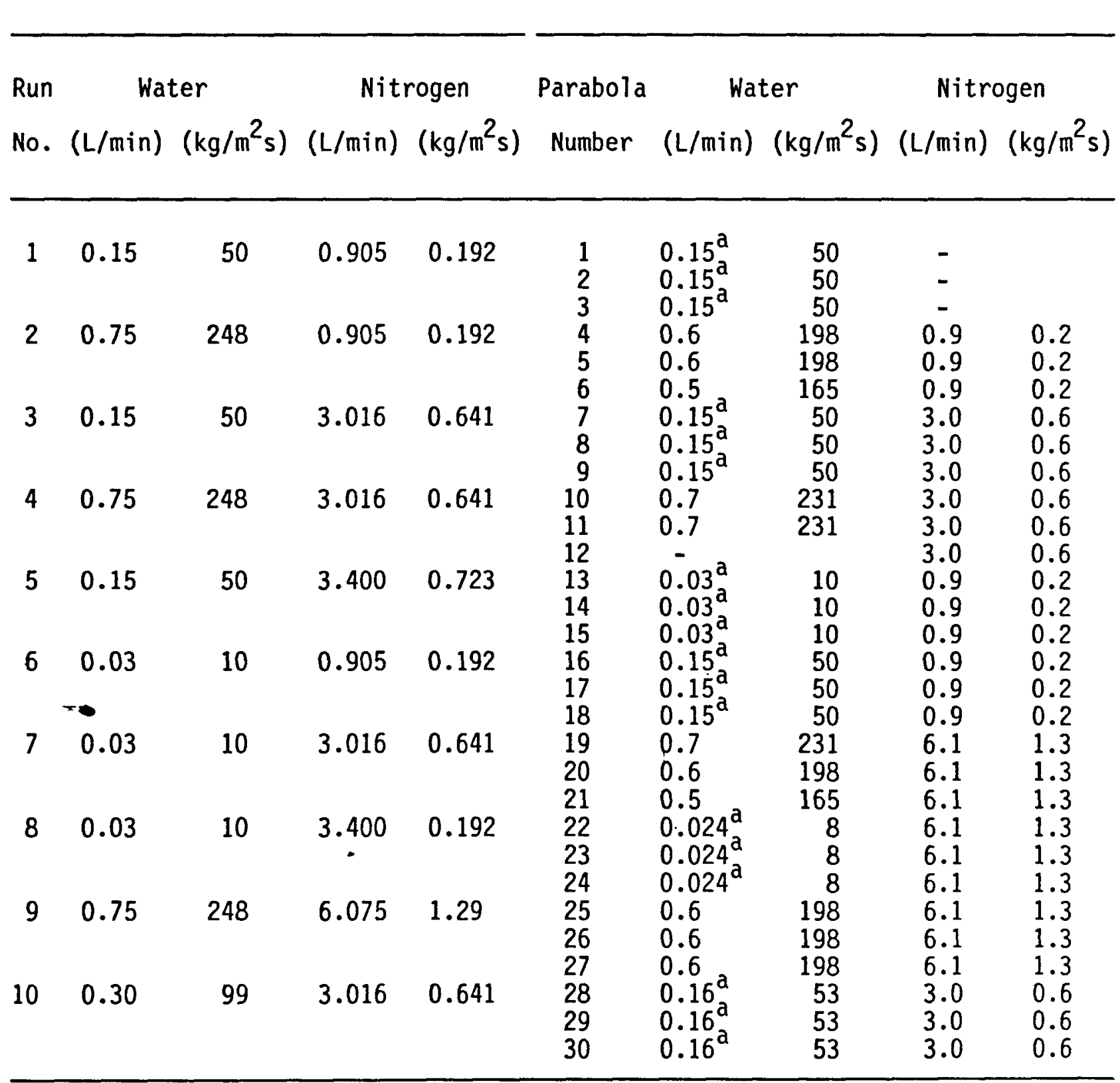

a Below the range of the turbine flowmeter; reported from rotameter reading before parabola

As-Run Flow Rates before parabola 
TABLE 4. Flow Regime Comparisons

\begin{tabular}{|c|c|c|c|c|c|c|}
\hline \multirow[b]{2}{*}{$\begin{array}{c}\text { Parabola } \\
\text { No. }\end{array}$} & \multirow[b]{2}{*}{$\begin{array}{c}\text { Flow } \\
(\mathrm{L} / \mathrm{min} .)\end{array}$} & \multirow[b]{2}{*}{$\begin{array}{l}\text { Power } \\
\text { (W) }\end{array}$} & \multicolumn{2}{|c|}{ BOILER } & \multicolumn{2}{|c|}{ CONDENSER } \\
\hline & & & COBRA/TRAC Prediction & $\begin{array}{l}\text { Experimentally } \\
\text { Observed Near Exit (a) }\end{array}$ & $\begin{array}{l}\text { COBRA/TRAC } \\
\text { Prediction }\end{array}$ & $\begin{array}{c}\text { Experimentally } \\
\text { Observed (b) }\end{array}$ \\
\hline 10 & Low $(0.4)$ & Low (1049) & $\begin{array}{l}\text { One phase with bubbly } \\
\text { near exit }\end{array}$ & Bubbly & Bubbly & -- \\
\hline 19 & Low $(0.3)$ & Low (2203) & $\begin{array}{l}\text { Half one phase, half } \\
\text { bubbly }\end{array}$ & -- & Annular & $\cdots$ \\
\hline 23 & Low $(0.4)$ & Low (1902) & -- & Annular/slug/dryout & $-\infty$ & $\cdots \cdot$ \\
\hline 14 & Low $(0.4)$ & $\begin{array}{l}\text { Intermediate } \\
(2783)\end{array}$ & $-\infty$ & -- & --- & Annular \\
\hline 15 & Low $(0.4)$ & $\begin{array}{l}\text { Intermed iate } \\
(3037)\end{array}$ & -- & Annular/froth/dryout & -- & -- \\
\hline 6 & $\begin{array}{l}\text { Intermedi- } \\
\text { ate }(0.6)\end{array}$ & $\begin{array}{l}\text { Intermediate } \\
(3200)\end{array}$ & --- & Annular/long slug & -- & $\cdots$ \\
\hline 17 & $\begin{array}{l}\text { Intermedi- } \\
\text { ate }(0.5)\end{array}$ & $\begin{array}{l}\text { Intermediate } \\
(3323)\end{array}$ & --- & Annular/froth/dryout & $-\cdots$ & Annular \\
\hline 21 & $\begin{array}{l}\text { Intermedi- } \\
\text { ate }(0.5)\end{array}$ & $\begin{array}{l}\text { Intermediate } \\
(2630)\end{array}$ & -- & Annular/slug/some dryout & -- & --- \\
\hline
\end{tabular}

\begin{tabular}{lll}
\hline & Flow $\left(\mathrm{kg} / \mathrm{m}^{2}-\mathrm{s}\right)$ & Power $(\mathrm{W})$ \\
Low: & $<150(0.45 \mathrm{~L} / \mathrm{min})$. & $<2300$ \\
Intermediate: & $150<\mathrm{m}<215$ & $2300<\dot{q}<3500$ \\
High: & $>215(0.65 \mathrm{~L} / \mathrm{min})$. & $>3500$
\end{tabular}

(a) Observed at point about $80 \%$ of total boiler length.

(b) Observed at center of condenser length. 


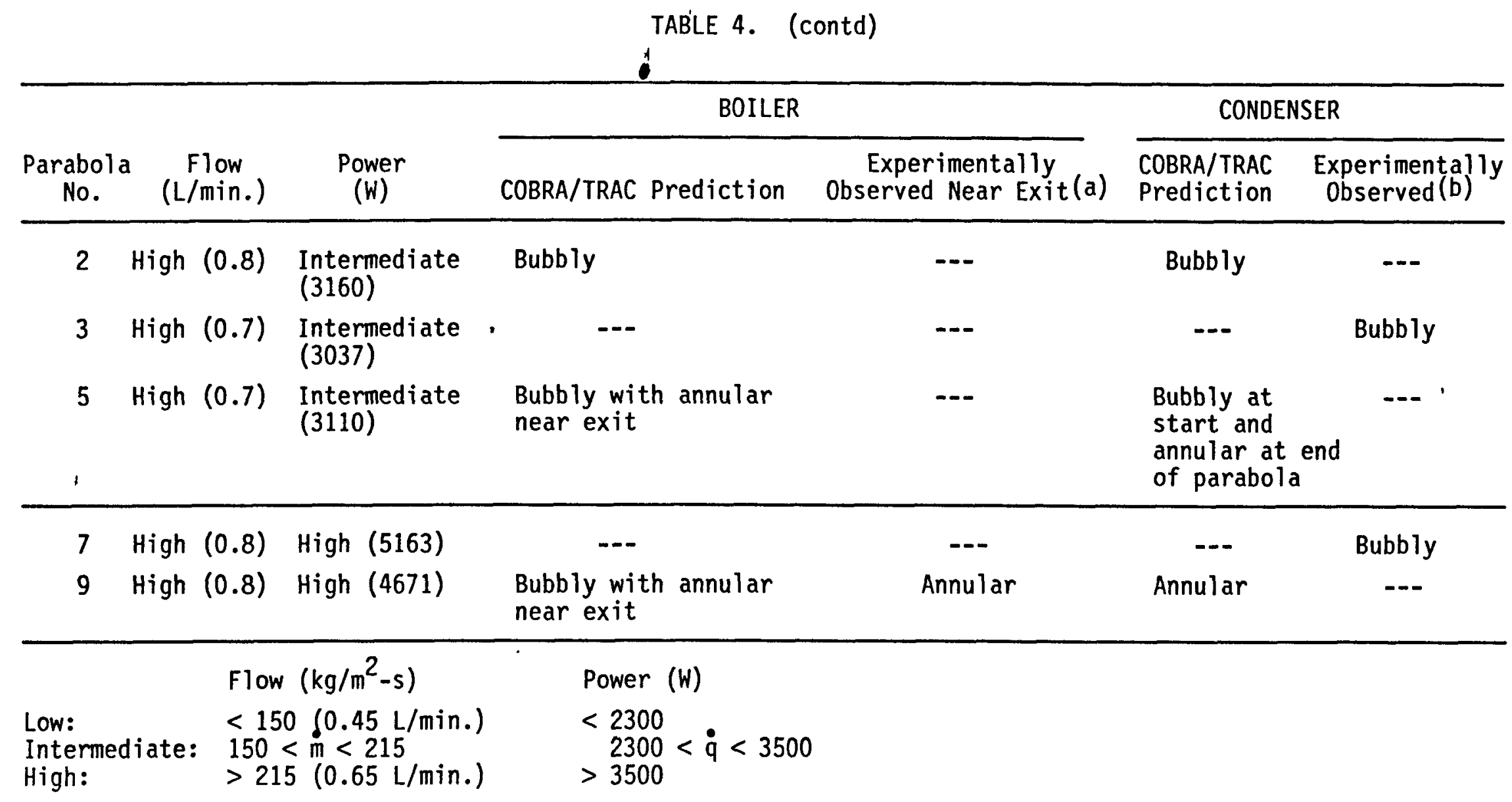

(a) Observed at point about $80 \%$ of total boiler length.

(b) Observed at center of condenser length. 


\section{Figure Captions}

1. Schematic of Boiling/Condensing KC-135 Experiment Apparatus

2. Instrumentation Measurement Locations for Boiling/Condensing Experiment

3. KC-135 Aircraft Vertical Acceleration During Parabola 10

4. COBRA/TRAC Model of Test Apparatus

5. Measured and Calculated Boiler Temperatures for Parabola 2

6. Measured and Calculated Boiler Pressure Drop for Parabola 2

7. Measured and Calculated Condenser Temperatures for Parabola 2

8. Measured and Calculated Condenser Pressures for Parabola 2

9. Measured and Calculated Boiler Temperatures for Parabola 9

10. Measured and Calculated Boiler Pressure Drop for Parabola 9

11. Measured and Calculated Condenser Temperatures for Parabola 9

12. Measured and Calculated Condenser Pressures for Parabola 9

13. Measured and Calculated Boiler Temperatures for Parabola 10

14. Measured and Calculated Boiler Pressure Drop for Parabola 10

15. Measured and Calculated Condenser Temperatures for Parabola 10

16. Measured and Calculated Condenser Pressures for Parabola 10

17. ATHENA Nodalization

18. Calculated and Measured Boiler Temperatures for Parabola 2

19. Calculated and Measured Condenser Temperatures for Parabola 2

20. Calculated and Measured Boiler Temperatures for Parabola 5

21. Calculated and Measured Condenser Temperatures for Parabola 5

22. Calculated and Measured Boiler Temperatures for Parabola 9

23. Calculated and Measured Condenser Temperatures for Parabola 9 